\title{
What is the Relation (if any) Between a Firm's Corporate Governance Arrangements and its Financial Performance?
}

\author{
Roberto E. Wessels* \\ University of Groningen, The Netherlands \\ Tom Wansbeek \\ University of Groningen, The Netherlands \\ Lammertjan Dam \\ University of Groningen, The Netherlands
}

We present a model to test the null hypothesis that firms organize their corporate governance arrangements optimally given the constraints they face. Following the literature, the model rejects the null if the conditional correlation between governance and performance is significantly different from zero. Our model provides a clean test of this hypothesis by controlling for measurement errors in all observed variables and avoiding simultaneous equation biases by casting our model as a reduced-form bivariate equation. We model governance, performance and the constraints on the firm's investment decisions as latent variables. We estimate of the conditional correlation between our measures of corporate governance and firm financial performance to be statistically speaking equal to zero. This result therefore provides empirical support for the in-equilibrium view of corporate governance arrangements. (JEL: C38, G34, L20, M52)

Keywords: corporate governance; optimal firm behavior; endogeneity; structural models; latent variables

\footnotetext{
* Corresponding author, r.e.wessels@rug.nl. The authors are with the Faculty of Economics and Business, University of Groningen, the Netherlands. This research was started when Wessels was at the McCombs School of Business of the University of Texas at Austin. The patience and forbearance of Chishen Wei in collecting and shaping the data are hereby gratefully acknowledged. We thank seminar participants in Austin and Groningen and participants of the 8th Portugese Finance Network International Conference, Vilamoura 2015, the 23rd Annual Multinational Finance Society Conference, Stockholm 2016, for their discussion contributions. We are indebted to Fernando Gascón, Laura Spierdijk and Sheridan Titman for providing many helpful suggestions.
}

(Multinational Finance Journal, 2016, vol. 20, no. 04, pp. 323-354)

(C) Multinational Finance Society, a nonprofit corporation. All rights reserved. DOI: $10.17578 / 20-4-2$ 
Article history: Received: 26 February 2016, Received in final revised form: 21 January 2017, Accepted: 01 February 2017, Available online: 04 July 2017

\section{Introduction}

In order to be successful, firms must develop and maintain mutually beneficial relations with various counterparties such as employees, capital providers, communities, suppliers, customers, regulators and competitors whose interests may conflict with those of the firms' owners. Managing these conflicts is complicated, particularly so for large, exchange-listed firms where the separation of ownership and control adds a layer of complexity as firms are owned by shareholders, but controlled by hired managers.

As a result, managers in these firms are expected to resolve conflicts of interest to which they often are an interested party. This has given rise to complex mechanisms designed to monitor the performance of the managers but also to provide them with incentives to act in the interest of the shareholders. We refer to the collection of these mechanisms as the structure of corporate governance. The main question we try to answer in this paper is whether firms organize their corporate governance arrangements optimally. To answer the question we rely on a sample of large, publicly traded firms, most of which belong or belonged to the S\&P1500 index during the period 2000 to 2008 .

Empirical research on corporate governance has been shaped by two contrasting approaches to how markets work: the in-equilibrium view and the out-of-equilibrium view, the former being credited to Demsetz (1983) and the latter to Berle and Means (1932). The main prediction of the in-equilibrium view is that firms configure their corporate governance arrangements optimally, given the constraints on their resources, while the out-of-equilibrium view denies that this is the case by documenting the behaviour of self-serving managers, as in Bebchuk and Fried (2004).

For a number of reasons, trying to distinguish between these two views of how markets work is not straightforward. First, there are strong theoretical reasons to assume that firms decide on how to allocate scarse resources to governance and production simultaneously. Governance and profitability therefore share common determinants, not all of which are necessarily observable. Thus, as has been argued by Hermalin and Weisbach (2003), unless this dependency on common determinants is accounted for, the estimates of the relations between governance and 
performance will be biased.

A second reason is that corporate governance arrangements are a black box, as noted by Cornelli, Kominek, and Ljungqvist (2013). Technically, corporate governance is an unobservable or latent variable. In the empirical literature corporate governance is therefore often measured by a proxy variable assumed to correlate with the true but unobservable latent variable, for example, a measure of the firm's equity owned by the management e.g. Demsetz and Villalonga (2001) or a measure of the size or structure of the board of directors e.g. Coles, Daniel and Naveen (2008). Thus, previous studies have analysed the relation between firm performance and corporate governance considering a single proxy of corporate governance and then drawing conclusions about the effects of changes in corporate governance in general under the assumption that "everything else" is kept constant. ${ }^{1}$

The main contribution of our paper is that we address both issues by estimating a reduced-form version of a structural model in which we postulate that firms choose their corporate governance arrangements in order to maximize their financial performance, subject to constraints. In particular, to both address measurement error and test the hypothesis that markets are in equilibrium, we estimate a bivariate, reduced-form model in which governance and performance are functions of the investment opportunity set and of unobserved other variables, collected in the error terms. In doing so, we model corporate governance, firm performance and the investment opportunity set as latent variables. ${ }^{2} \mathrm{We}$ can reject the in-equilibrium view if the covariance between the error terms of the two equations significantly differs from zero as that would indicate that governance and performance share a common source of (residual) variability after accounting for the variation in the investment opportunity set.

Our paper has two main results. First, we show that the unconditional correlation between corporate governance and financial performance is positive and statistically highly significant, $\rho=0.694$ with a $t$-value of 17.17. This result can be interpreted, absent other considerations, that an increase in our measure of corporate governance is associated with an increase in our measure of financial performance. By estimating a regression of performance on governance, we could show that the regression coefficient is statistically highly significant.

1. For a critical view of this practice see Coles, Daniel, and Naveen (2008), p.3, and Adams, Hermalin, and Weisbach (2010), p.62.

2. For textbook treatments of models with latent variables, see Wansbeek and Meijer (2000) and Skrondal and Rabe-Hesketh (2004). 
However, in that case, the correlation is measuring association and not causation since the estimate does not take into consideration the opportunities and constraints that firms face when taking allocation decisions. In fact, the estimated unconditional correlation is a measure of what the relation between governance and performance would be if governance were a free good; Jensen and Meckling (1976) refer to this way of reasoning as Nirvana analysis.

Perhaps more realistically, the in-equilibrium view implies that, if technical and market conditions vary across firms such that firms operating in different markets and industries face different investment opportunities, we should not expect corporate governance arrangements and financial performance across firms to be correlated once the differences in opportunities and constraints across firms are taken into account.

Our second main result is that we estimate the covariance of the error terms of the structural equations to be -0.05 , with a $t$-value of -0.61 , and so we have no reason to reject the in-equilibrium view. In other words, the correlation between governance and performance conditional on the firm's investment opportunity set is zero. Note that we can exclude the interpretation that this result is due to governance and performance being generally unrelated, as we also show that the unconditional correlation between governance and performance is large and statistically significant. In sum, our findings provide support for the in-equilibrium view and suggest that firms choose their corporate governance arrangements optimally.

The paper proceeds as follows. In the next section we elaborate on the discussion in the existing literature. In Section III we present the model used to test the equilibrium view. We discuss the specification and how the model is estimated. To estimate the model we also need to specify the indicators used to measure the latent variables of the model. These indicators are discussed with reference to the literature in Section IV. The results are presented and discussed in Section V. The conclusions of the paper are summarized in Section VI.

\section{Literature review}

Over the past thirty years, since the seminal work of Demsetz and Lehn (1985), academic researchers have devoted much energy to investigate whether firms with effective corporate governance arrangements are also the firms with better financial performance. Empirical research has 
been shaped by two contrasting approaches to how markets work, the in-equilibrium view (Demsetz, 1983) and the out-of-equilibrium view (Berle and Means, 1932). According to the in-equilibrium view, what we observe in the data is assumed to be the result of firms making value-maximizing decisions subject to constraints. This then suggests the conjecture that, if the equilibrium view is correct, we should not be able to observe any conditional correlation between governance and performance.

The proponents of the out-of-equilibrium view, on the other hand, hold that empirically observed correlations between measures of corporate governance and firm performance imply that firm performance can be improved by increasing the effectiveness of corporate governance. This position begs the question why firms apparently pass up on opportunities to improve their bottom line. One possible explanation is that an out-of-equilibrium situation arises when the balance of control over the firm is held by entrenched managers whose interests are not aligned with those of shareholders; see Bebchuk and Fried (2004) and the comments by Holmstrom (2005).

The difference between these two views is not obvious. First, governance and performance are likely to share common determinants. Unless this interdependency is accounted for, estimates of the correlation between governance and performance will be biased (Hermalin and Weisbach, 2003). Second, corporate governance arrangements are a "black box" (Cornelli, Kominek, and Ljungqvist, 2013). Corporate governance is a theoretical construct, not an observable variable. In most of the literature, corporate governance is measured by a proxy variable that is assumed to be somehow correlated with the true (unobservable) latent variable.

Measuring corporate governance in this way has several drawbacks. First, proxy variables are by definition subject to measurement error, which induces endogeneity when these variables are used in regression analysis, cf. Erickson and Whited (2006). As the use of proxy variables is ubiquitous, proxies are an endemic cause of endogeneity. ${ }^{3}$ Moreover, most of the common proxies of corporate governance arrangements are correlated, suggesting that corporate governance arrangements include substitutes and complements. Examples of corporate governance mechanisms that work as complements are given in Cremers and Nair

3. For a general treatment of endogeneity, see Roberts and Whited (2012), and for a (pessimistic) discussion of the generally applied remedies to endogeneity problems in empirical corporate finance, see Coles, Lemmon, and Meschke (2012). 
(2005); examples of mechanisms that work as substitutes are provided in Hartzell and Starks (2003).

We are by far not the first to study the relation between corporate governance and financial performance. Here, we discuss three widely quoted papers, which are closely related to this study, but which have followed different approaches in reaching their results: Demsetz and Villalonga (2001); Johnson, Moorman, and Sorescu (2009) and Wintoki, Netter, and Linck (2012).

These are of course well-known and widely quoted papers, which however, in our opinion do not provide an answer to the question "What is the empirical relation between corporate governance and firm performance?". What these papers present are the results of regressions of performance on structural relations or vice versa, using observable proxies of the latent variables corporate governance and firm performance. Unless we are willing to accept that the proxies are perfect measures of corporate governance and firm performance, the reported estimates will not provide reliable information about the relation between governance and performance.

Empirical research has struggled with the problem that the observable data available to the researcher, even in the best of cases, are the fallible traces that the underlying latent variables leave on the observable data. For example, all the companies in our sample are required by law to have a Board of Directors. In the literature, the Board of Directors is considered to be the most important arrangement of the firm's corporate governance (see Adams, Hermalin, and Weisbach., 2010). What we know about the Board of Directors is in the data collected about observable characteristics of its members and by the decisions the board takes and are available in the public domain. For example, we can look up the number of members serving on the Board of Directors and treat that as an indicator of the firm's corporate governance in much the same way that we treat an answer to a question on the SAT as an indicator of a student's scholastic aptitude. Note that in the case of the SAT nobody would confuse the answer to question or even the result of the complete test with a student's scholastic aptitute. The answers to the test, and the score derived therefrom are a (fallible) indicator of the students' unobservable, true scholastic aptitude. We think of the SAT score as a predictor of a student's scholastic aptitude but try to keep in mind that the predictor is not perfect. Another way of putting it is to say that we know that the score on the SAT contains errors of measurement and we therefore try to adjust the score for such 
errors. The corporate governance literature however, has not been so careful since what is missing in the previous literature is an explanation of how the results obtained by estimating relations with proxies can be translated to results that apply to the latent variables that are the object of the theories whose implications we wish to test.

Of course, one could dismiss this objection as being inconsequential or irrelevant or even trivial. However, given the attention that the empirical literature pays to endogeneity issues, starting with Demsetz and Lehn (1985), it is somewhat surprising to note that errors of measurement, which arise when a proxy is used instead of the true variables, and which are a major source of endogeneity (see Roberts and Whited, 2012), has not been addressed in the empirical corporate governance literature.

How do the above-mentioned studies of Demsetz and Villalonga (2001), Johnson, Moorman, and Sorescu (2009), and Wintoki, Linck, and Netter (2012) fare in this respect?

The Demsetz and Villalonga (2001) study marks a milestone in the empirical corporate governance literature because it pushed back on previous findings, starting with Morck, Shleifer, and Vishny (1988), which had found an inverted U-shaped relation between Tobin's Q, a proxy of relative firm value, and measures of ownership of the firm by management. In these studies, as the percentage of management ownership increased, financial performance first increased, but performance started to decrease when ownership was increased beyond a certain level. As Demsetz and Villalonga (2001) show, this relationship between ownership and performance vanishes when the endogeneity of the indicators for management ownership and firm performance are taken into account. These results are not only well-known, but also, as far as we can determine, undisputed. However, unless one adopts the position that the observable variable "share ownership by management" is in fact equivalent to the latent variable "corporate governance" and, moreover, that the various measures of financial performance that the authors include in their analysis are free of measurement errors when used to measure the latent variable "firm performance", their analysis has no implications for the relation between the latent variables "corporate governance" and "firm performance". But then again, neither do Demsetz and Villalonga (2001) make any claims in that respect.

Johnson, Moorman, and Sorescu (2009), re-examine the relation between stockholder returns and the so-called G-index, a proxy of 
corporate governance due to Gompers, Ishii, and Metrick (2003). Their paper on p4780 issues a clear warning of the biases that can arise when a variable that is measured with error is used in a regression, but no further mention of these concerns is made when the results of the regressions (using proxy variables for corporate governance) are discussed. By then, the errors-in-variables problem has seemingly been forgotten.

In their paper, Wintoki, Linck, and Netter (2012), p. 603, state: "However, we argue that empirical research often overlooks an important source of endogeneity that arises because the relations among a firm's observable characteristics are likely to be dynamic. That is, a firm's current actions will affect its control environment and future performance, which will in turn affect its future actions." In our paper, we take a different approach by controlling for fixed time (and industry) effects expressing all variables in deviation of their time-series and industry averages (see the Data section of this paper where we explain how we construct our variables).

Our conclusion is that although these three papers, which are representive of the many papers in this area, are certainly aware of the errors-in-variables problem, we believe that, however extensively and meticulously the results of these studies may have been documented, that the errors-in-variables problem stemming from the use of proxies to represent unobservable or latent variables has been largely ignored in the previous literature, and that as far as we have been able to establish, all the available results are likely to be biased due to the errors-in-variables problem. In that respect, the contrast between the previous literature and our paper is quite stark.

Finally, we acknowledge that not all observed corporate governance arrangements are freely chosen by the firms. Some features of corporate governance are the result of legal or regulatory requirements. Recent examples of regulatory changes are the Sarbanes-Oxley Act of 2002, which set new standards for how companies report their results, see Chhaochharia and Grinstein (2007); the requirement that the majority of the members of the board of directors of all NYSE and NASDAQ listed firms be independent (Coles, Daniel, and Naveen (2008); Duchin, Matsusaka, and Ozbas (2010)); and the introduction of gender quotas for boards of directors, recently introduced in Norway (Ahern and Dittmar, 2012, and Bøhren and Staubo, 2014). ${ }^{4}$ These studies provide

4. For a dissenting view of the effects of a gender quota in Norway see Eckbo, Nygaard and Thorbrun (2016). 
evidence that such exogenous changes can have large value-destroying effects on firms. Indicating that if the constraints imposed by legal requirements and regulations are binding from above, optimal performance in the new situation will be strictly lower than in the optimum prior to the regulatory change.

There can be all kinds of reasons why such changes should be imposed on firms. One reason could be that there are externalities that firms do not take into account when considering their corporate governance arrangements, like the systemic risks posed by financial firms which has lead to these firms being subject to industry-specific forms of regulatory controls. But, whatever the reason, contributing to the improvement of the financial performance of firms is not one of them.

This completes our discussion on the difficulties of establishing a link between corporate governance and financial performance. In the next section we next propose an empirical approach address these issues.

\section{A model of the relation between corporate governance and firm financial performance}

With the index $i$ denoting firms, let $G_{i}$ be the actual level of corporate governance, $G_{i, \text { ОРт }}$ the optimal level of corporate governance, $F_{i}$ financial performance, and $I_{i}$ the investment opportunity set, assumed exogenous. We propose a three-equation model, where actual and optimal corporate governance and financial performance are driven by the investment opportunity set, and financial performance suffers quadratically when the level of corporate governance is suboptimal:

$$
\begin{gathered}
G_{i, \mathrm{OPT}}=\kappa_{\mathrm{OPT}}+\theta_{\mathrm{OPT}} I_{i} \\
G_{i}=\kappa+\theta I_{i}+u_{1 i} \\
F_{i}=\alpha+\lambda I_{i}+\beta\left(G_{i}-G_{i, \mathrm{OPT}}\right)^{2}+u_{2 i}
\end{gathered}
$$

The error terms $u_{1 i}$ and $u_{2 i}$ are assumed independent of $I_{i}$ and to be normally distributed, with means zero and variances $\sigma_{u 1}^{2}$ and $\sigma_{u 2}^{2}$, respectively, and covariance $\gamma$. As we show in appendix A, substitution 
of (1) and (2) into (3) yields the reduced-form expression for $F_{i}$,

$$
F_{i}=\alpha^{\prime}+\lambda^{\prime} I_{i}+e_{i}
$$

with the parameters $\alpha^{\prime}$ and $\lambda^{\prime}$ and the error term $e_{i}$ defined in the appendix. There we also show that $e_{i}$ is independent of $I_{i}$ and that its covariance with $u_{1 i}$ is given by

$$
E\left(u_{1 i} e_{i}\right)=\beta\left(u_{1 i} w_{i}\right)+\gamma=2 \beta c \sigma_{u 1}^{2}+\gamma,
$$

with $c \equiv\left(\kappa-\kappa_{\mathrm{OPT}}\right)+\left(\theta-\theta_{\mathrm{OPT}}\right) \mathrm{E}\left(I_{i}\right)$. We can estimate this covariance by simply estimating the reduced-form model consisting of (2) and (4).

This covariance between error terms, which equals the covariance between corporate governance $G_{i}$ and financial performance $F_{i}$, is at the core of our analysis. In particular we are interested in the question whether this covariance (or, for that matter, the corresponding correlation) equals zero, as that would mean the following: excluding a freak constellation of parameter values and assuming $\beta \neq 0$ (i.e., governance affects performance), zero covariance means that both terms are zero, so $\gamma=0$ and $c=0$; the latter would reasonably mean $\kappa=\kappa_{\mathrm{OPT}}$ and $\theta=\theta_{\mathrm{OPT}}$. In words, governance is on average optimally determined and deviations from the optimum are not systematic in the sense of being correlated with the opportunity set. So $\bar{G}=\bar{G}_{\text {OPT }}$.

When it comes to actually estimating the reduced form, we notice again that none of the three variables can be directly observed; they are latent variables. So our estimation will be indirect, through the use of proxy variables in a factor analysis structure. That means that we postulate for the latent variable $G_{i}$ the model with $k$ (say) proxies $y_{l i}, \ldots, y_{k i}$

$$
\begin{gathered}
y_{1 i}=G_{i} \lambda_{1}+\varepsilon_{1 i} \\
\vdots \\
y_{k i}=G_{i} \lambda_{k}+\varepsilon_{k i}
\end{gathered}
$$

with $\lambda_{1}, \ldots, \lambda_{k}$ the factor loadings and $\varepsilon_{1 i}, \ldots, \varepsilon_{k i}$ the error terms, independent of $G_{i}$. We use the same structure for the other two latent variables, $F_{i}$ and $I_{i}$. The proxies that we will use when estimating our model are discussed in more detail in the next section. 


\section{The proxies of corporate governance, firm performance, and the investment opportunity set}

In this section we discuss the indicators that will be used to measure the latent variables of our model, $G, F$ and $I$ as discussed in Section III. To make them easily identifiable amidst a variety of other variables, we write them in the mnemonically easier form CORP-GOV, FIN-PERF, and INV-OPP. From here on we use italic capitals to denote latent variables and straight capitals for proxies. Appendix B provides a definition of the observable variables and lists their source.

\section{A. The proxies of corporate governance}

CORP-GOV, is the latent variable used to characterize the effectiveness of the arrangements firms put in place to align the interests of the providers of capital with the interests of those who control and manage the firm. This is a complex and multifaceted concept which is not directly observable. In our model, it is measured indirectly using four proxy variables chosen to reflect the salient aspects of the structure of corporate governance.

Our first proxy BSIZE is a measure of the structure of the board of directors. BSIZE is measured as the logarithm of 1 plus the number of board members. According to Adams, Hermalin, and Weisbach (2010), the board of directors is the most important mechanism of the firm's corporate governance. In studying the role of the board, the literature has relied on measuring the structure and the composition of the board (Coles, Daniel, and Naveen 2008); how the board members are compensated (Ryan and Wiggins, 2004); whether the board members have business dealings with the firm or are independent (Cohen, Frazzini, and Malloy, 2012); whether they hold concurrent appointments at other boards and are there fore maybe too busy (Fich and Shivdasani, 2006); and even their geographical proximity to the firm (Lehn, Patro, and Zhao, 2009).

BSIZE as a measure of the board of directors has received considerable attention in the literature following concerns (Jensen, 1993) that if the size of the board became (too) large its effectiveness would decrease. Early empirical studies (Yermack, 1996) showed that firms with smaller boards performed on average better that firms with large boards. Later studies (Boone, Field, Karpoff, and Raheja, 2007; Coles, Daniel, and Naveen, 2008; and Linck, Netter, and Yang, 2008) 
showed that board size is being endogenously determined as a function of the firm's advising and monitoring requirements.

The second proxy of CORP-GOV is a measure of the CEO's compensation package (CEO-COMP). Fahlenbrach (2009) argues and provides some evidence showing that the CEO's compensation package is an important instrument the Board of Directors uses to manage the conflicts of interest between shareholders and management.

Despite many efforts to shine a light on executive compensation practices, see the review in Murphy (2013), measuring the size and composition of the CEO's compensation package remains a difficult task, to put it mildly. In part, the reason for this is that the data collected refers only to what firms are legally required to report. Another reason is that compensation is provided under many different guises and time dimensions: salary, bonus, equity options, outright and restricted stock grants, and retirement benefits which must be translated into dollar values before they can be added to give an estimate of the size of the package.

Our definition of CEO-COMP is taken from Frydman and Saks (2010). In addition, we follow Gabaix and Landier (2008) by assuming that a CEO's productivity is a function of firm size and scale the dollar amount of compensation by the firm's total assets to adjust for this.

The number of institutions holding shares in the firm, INST-INV, is the third proxy of CORP-GOV. We measure INST-INV by the log of 1 plus the number of institutions holding shares in the firm.

Institutional investors have no formal role in the firm's corporate governance structure other than that of being a shareholder. But the size of the institutions and the influence they can wield turns them into shareholders that are to be regarded by management as being more equal than other shareholders. In Almazan and Suarez (2003) and Hartzell and Starks (2003) evidence is presented indicating that institutional investors actively monitor the CEO's compensation packages of the firms they invest in. In Bushee, Carter, and Gerakos (2014) and McCahery, Starks, and Sautner (2016) evidence is presented showing that institutional investors select the firms in which they invest on the basis of how they evaluate the corporate governance practices of the target firm. We interpret these preferences as causal determinants of observed corporate governance arrangements.

Our final proxy of CORP-GOV is SHR-OWN, the percentage of the firm's outstanding shares owned outright by the firm's management. The measure does not include option grants, which are accounted for in 
CEO-COMP. In the early literature (Demsetz and Lehn, 1985 and Morck, Schleifer, and Vishny, 1998), when the term corporate governance had not yet gained currency, share ownership by management was used to measure the scope of potential conflicts between management and shareholders. A more recent paper by Coles, Daniel, and Naveen (2012) continues that tradition but includes options granted to management in the measure). We include SHR-OWN as a proxy to facilitate comparison.

We have chosen not to include in our list of observable indicators of CORP-GOV the governance index of Gompers, Ishii, and Metrick (2003). This latter study has been widely quoted and the findings critically debatted in the literature. A question that has raised much attention is related to answering which provisions or by-laws are important and which are not (see Cremers and Nair, 2005; and Stráska and Waller, 2010). Another question is whether these provisions have any impact on firm performance. For instance, Johnson, Moorman, and Sorescu (2009) show that there is no relation between the a firm's score on the G-index and returns on the firm's shares once industry effects have been taken into account. In our paper we adjust the data for industry and time effects.

Finally, one may object to the fact that our study omits to include so-called control variables such as can be found in Bhagat and Bolton (2008) or Coles, Daniel, and Naveen (2008). These control variables are generally included in the regressions in order to conduct analyses of the estimated coefficients under the ceteris paribus clause. This point is well-taken, but if we have an omitted variables problem then that would work against rejecting the null-hypothesis of no correlation between the error terms of the reduced-form regressions since omitted variables are a common source of endogeneity which would precisely induce correlation between the errors terms of the reduced-form equations. This, in turn, would lead us to having to accept the null-hypothesis that governance and performance are conditionally correlated.

A more general problem is that we do not know whether such provisions represent good or bad governance (see Brickley and Zimmerman, 2010; and Stráska and Waller, 2010), even though the usage can be found in the literature, e.g. Dittmar and Mahrt-Smith (2007). In addition, the theoretical foundations of commercially produced corporate governance ratings which purport to measure corporate governance on an ordinal scale is weak, to say the least (see on this matter Bhagat, Bolton, and Romano (2008); and Daines, Gow, and Larcker, 2010). 


\section{B. The proxies of financial performance}

The concept of FIN-PERF, is perhaps not a black-box like CORP-GOV, yet there seems to be little agreement in the literature as to how firm financial performance should be measured.

There are three types of data: measures of the firm's relative value, such as Tobin's Q; accounting measures of financial performance, such as ROA and returns on the firm's equity derived from stock market prices. The lack of consensus as to how financial performance should be measured suggests that we can safely assume that no "true" measure exists and that all these observable performance measurements are to some degree subject to errors of measurement.

Our model uses three indicators to measure performance: FCF, a measure of the firm's free cash-flow, which uses accounting data in its calculation; STK-RET, the market return of the firm's equity and VOL, a measure of the volatility of the firm's stock returns. FCF is a proxy of the free cash-flow concept due to Jensen (1986). According to Jensen, free cash-flow measures the resources generated by the firm that management could distribute to the shareholders in the form of dividends without impairing the current value of the firm. FCF is very similar to the more commonly used ROA performance measure. The difference with FCF is that ROA includes the effects of discretionary accruals and deferrals of certain cash flows to earlier or later periods and is therefore susceptible to what is euphemistically referred to as earnings management.

According to Holmstrom and Tirole (1993), STK-RET, the market-determined return on the firm's equity, reflects the aggregate market's assessment of the firm's financial outlook and is therefore a valid proxy of the firm's financial performance.

VOL measures the volatility of the firm's equity returns. VOL is not a commonly used as a proxy of firm performance. An exception is perhaps Demsetz and Lehn (1985), who use volatility as a proxy for the instability of the firm's environment. Here we follow the accounting (Dichev and Tang, 2009) and asset pricing literature (Ang et al., 2006), which finds evidence that stock returns and the volatility of stock returns are significantly negatively correlated, suggesting that volatility is an indicator of FIN-PERF.

\section{The proxies of the investment opportunity set}

The firm's investment opportunity set, INV-OPP, is the only exogenous 
variable in our model. In the framework of the equilibrium view, INV-OPP is the determinant variable driving the choices over corporate governance arrangements and financial performance.

Our approach to measuring INV-OPP is not entirely without precedent. At least three earlier papers have measured INV-OPP using similar methods and similar proxy variables: Gaver and Gaver (1993), Guay (1999), and Coles, Daniel, and Naveen (2008).

To measure the latent variable INV-OPP we rely on three indicators. The first is SPINDEX, a categorical variable that classifies a firm into one of four categories depending on whether it belongs to one of the three indices that make up the S\&P1500 and, if so, to which of the three sub-indices it belongs. SPINDEX captures both the differences in size between firms and the differences in the firm's complexity arising from the differences in exposure, compliance and disclosure requirements that come with being included in one the major stock market index. The measure is increasing in the importance of the index with the S\&P500 categorized as the most important.

The second proxy is RD-SE, a measure of the firms' expenditures on intangible assets. These assets, which are often part of long-lasting projects, are difficult to value and require specific expertise in order to be effectively monitored. There is some evidence that corporate governance arrangements are associated with the specific monitoring requirements of this type of investments (see Boone et al., 2007, and Coles, Daniel, and Naveen, 2008).

Our final indicator is MTOB, the ratio of the market value to the book value of the firm, an approximation of Tobin's Q (Tobin and Brainard, 1977). The idea to treat MTOB as a measure of the firms ex ante growth opportunities is due to Myers (1977).

An early paper using MTOB as a determinant of corporate financial policies is Smith and Watts (1992). MTOB is a standard proxy for the firm's growth opportunities (see Boone et al., 2007; Linck, Netter, and Yang, 2008 and Lehn, Patro, and Zhao, 2009). What is interesting to note is that these studies, recognizing that the investment opportunity set is unobservable, also used factor analysis techniques to construct variables using similar proxies and techniques as those used in this paper.

We also note that there is also a considerable literature, starting with Morck, Schleifer, and Vishny (1998) and more recently Coles, Daniel, and Naveen (2012), in which MTOB serves as a proxy for firm performance. Arguing against this practice, Demsetz and Villalonga 
(2001) consider MTOB to be measure of relative value, thus skewed towards so-called growth firms and therefore not an unbiased reflection of the firm's performance. Dybvig and Warachka (2015) argue that for theoretical reasons Tobin's Q does not measure financial performance. For a lucid discussion of the different interpretations of Tobin's Q or q, see Roll and Weston (2008).

\section{Data}

We sample firms from the years 2000 through 2008 (9 years). Our initial sample consists of 15339 firm/year observations. We drop 1087 observations belonging to firms with no assets, no sales, no employees, no shares outstanding or with negative book equity. We then drop a further 3010 observations from firms belonging to the financial or utility sectors. At this point the sample consists of 11242 observations.

We then select in each year, firms with complete data records, meaning that in order for a firm to be included in the sample it must have a complete record, in at least one year, of the 10 variables used in our model. This leaves us with with 8567 observations. The missing information pertains mostly to the beginning of the sample period. Out of the 2675 dropped observations, 2062 were lost because no information was available on the composition of the board of directors; 325 because of missing information on the CEO's compensation; 65 had no stock market returns. Some firms missed more than one variable in a given year, which is why the sum of the missing observations is larger than the total number of deleted firm/years.

Before estimating the model, the data has been adjusted in the following way. First, all observations have been winsorized at the $1 \%$ and $99 \%$ level. Next, from each observation we subtract the industry and time period mean and add back the overall mean. Using the adjusted observations as our unit of analysis is equivalent to using the residual of a variable regressed on time and industry dummies. The transformation adjusts the data for the impact of shocks that affect all firms in a given time period while the correction for industry effects addresses the finding in the literature that firms tend to emulate their industry peers (Leary and Roberts, 2014)

The observations belonging to the same firm are averaged over time resulting in a cross-section of 1551 firms. This data is then standardized to variables with mean zero and unit standard deviation and used as the input for our estimation model. The data are summarized in appendix C. 
There are two reasons for collapsing the panel data set into a cross-section. First, changes in corporate governance happen infrequently. Since we only have nine years of data, any result we find will be to a large extent a cross-sectional result. Second, there may be timing issues; a change in corporate governance may not have a contemporaneous effect on financial performance, but could require a few years to materialize. An issue is then to figure out how many lags in estimating a dynamic panel model is appropriate. By focusing on differences in the cross section of medium-term averages of both financial performance and governance, we acknowledge that we perhaps loose some power in our tests and ignore potential dynamic relationships, but we argue that doing so allows for a "cleaner" interpretation of the results. See also Wintoki, Linck and Netter (2012).

\section{Model and estimation}

With the proxies thus introduced and motivated, the relation between the latent variables and the proxies can be represented as in figure 1 . We now formulate the model to be finally estimated. We start from the reduced-form model from Section III. Since $G_{i}, F_{i}$ and $I_{i}$ are latent, we can set their means equal to zero at no cost and omit intercepts. So the reduced-form model simply is

$$
\begin{aligned}
& G_{i}=\theta I_{i}+u_{1 i} \\
& F_{i}=\lambda^{\prime} I_{i}+e_{i}
\end{aligned}
$$

We omit subscripts indicating firms, use the longer notation CORP-GOV and FIN-PERF, and add the modeling of the proxies. The resulting equations of the model to be finally estimated are given in table 1.

Our main research question is whether there is residual covariance between CORP-GOV and FIN-PERF after accounting for the effect of INV-OPP.

The top panel of the table contains the regressions of governance and performance on the investment opportunities, the "structural model". The two error terms, $u_{1}$ and $e$, are allowed to correlate, as is indicated in the last column of the table. Whether this correlation is 


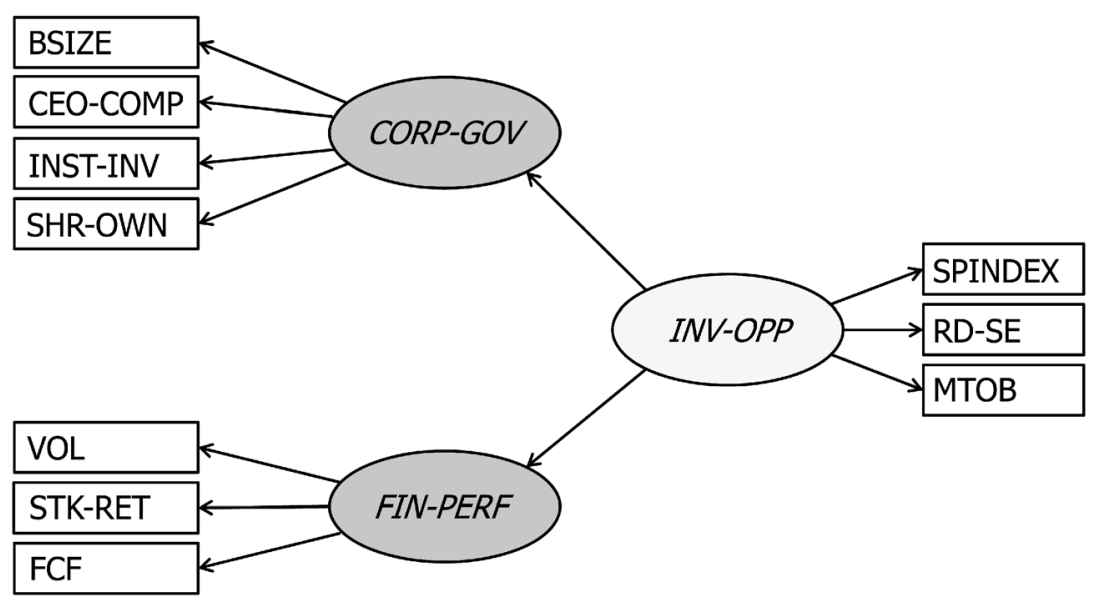

FIGURE 1.- The Relation between the Latent Variables and the Proxies.

Note: This figure shows the nature of the relations in our structural equation model. The latent variables are corporate governance (CORP-GOV), financial performance (FIN-PERF), and the investment opportunity set (INV-OPP). The observed proxies for corporate governance are board size (BSIZE), CEO compensation (CEO-COMP), institutional investors (INST-INV), and outstanding shares held by management (SHR-OWN). The observed proxies for financial performance are stock return volatility (VOL), stock returns (STK-RET), and free cash flow (FCF). The observed proxies for the investment opportunity set are index category (SPINDEX), investments in intangible assets (RD-SE), and market-to-book value (MTOB).

significantly different from zero is the main issue at stake in this paper.

The other three panels of the table, the "measurement model" together, contain the equations linking the three latent variables to the ten proxies. In the basic specification of our model, the matrix containing the ten variances and 45 covariances of the error terms is specified to be diagonal. Thus we start with 45 restrictions on this matrix. The software used to estimate the model provides diagnostic tools to evaluate these restrictions. This led us to free four of the 45 restricted error covariances. As is indicated in the last column of the table, these are the error covariances involving BSIZE and INST-INV, CEO-COMP and STK-RET, STK-RET and RD-SE, and STK-RET and MTOB.

There are plausible reasons for finding statistically significant covariances between these error terms. For instance, BSIZE and 
TABLE 1. Main model equations

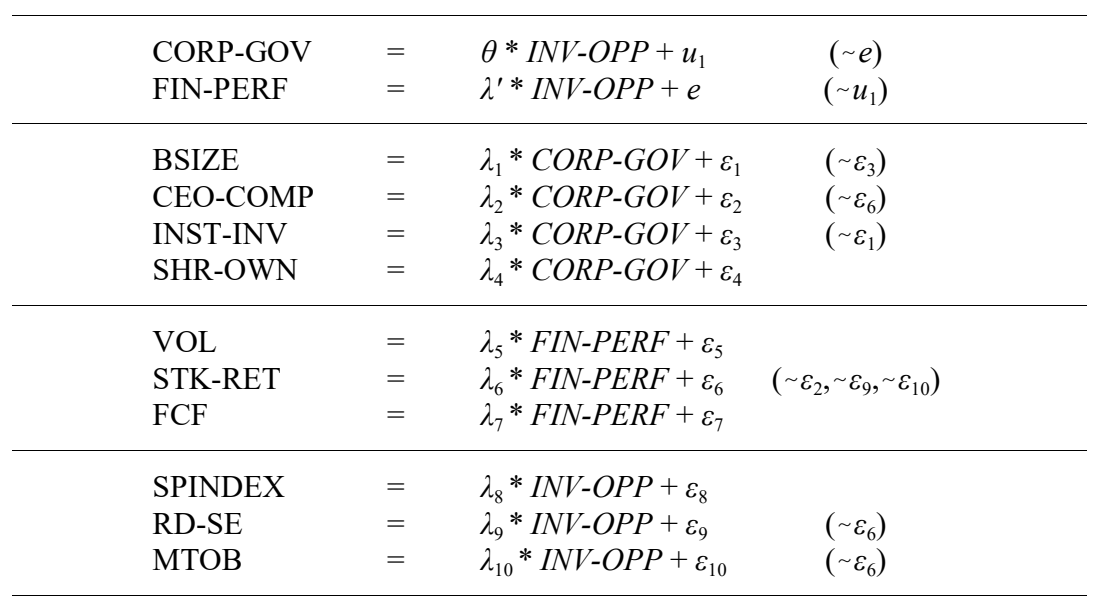

Note: This table shows the equations for our structural equation model. For some of the equation, the error is correlated with the error term in one or more of the other equations; this is indicated in the last column. The latent variables are corporate governance (CORP-GOV), financial performance (FIN-PERF), and the investment opportunity set (INV-OPP). The observed proxies for corporate governance are board size (BSIZE), CEO compensation (CEO-COMP), institutional investors (INST-INV), and outstanding shares held by management (SHR-OWN). The observed proxies for financial performance are stock return volatility (VOL), stock returns (STK-RET), and free cash flow (FCF), and . The observed proxies for the investment opportunity set are index category (SPINDEX), investments in intangible assets (RD-SE), and market-to-book value (MTOB).

INST-INV are both highly correlated with firm size. Large firms tend to have large boards and institutional investors tend to invest in the stock of large companies; CEO-COMP and STK-RET tend to move in response to common economic factors; STK-RET and RD-SE are negatively correlated since growth firms are highly dependent on financing by issuing equity, which is difficult to do when equity markets are losing value; and STK-RET and MTOB are mechanically correlated as the numerator of MTOB moves in unison with STK-RET, while the denominator changes much more slowly as new stock is issued or profits are retained.

All variables in the model are standardized to have mean zero and variance one. For the observed variables this means a data transformation. For the latent variables it is a simplifying assumption that can be made without any loss of generality.

The model is estimated in a GMM framework. The data are 
condensed to their covariance matrix, which in the case of standardized variables is an observed correlation matrix. Under the model, the elements of the matrix can be expressed as functions of the model parameters whose number preferably is much less than the number of elements in the matrix; the theory imposes a testable structure on the data. Estimation in this context essentially means that parameter values are sought that lead to a theoretical structure that resembles the observed structure as closely as possible.

Here, we adopt this procedure. We have ten proxies and hence, taking the symmetry of the correlation matrix into account, 55 variances and covariances are available for estimation purposes. The number of parameters driving these 55 variances and covariances is 29 , that is, $\beta, \lambda^{\prime}, \lambda_{1}, \ldots, \lambda_{10}$, three parameters in the covariance structure of $u_{1}$ and $e$, ten variances of the $\varepsilon$ 's, plus the four covariances between them that were allowed to be non-zero. The model was estimated using the Structural Equations Model (SEM) module in STATA version 12, by Weighted Least Squares.

\section{Results}

Our main empirical results come from the regressions of governance and performance on investment opportunities. The results, displayed in table 2 ( $t$-values in parentheses) clearly indicate that the investment opportunity set is a significant determinant of corporate governance and financial performance. The regressions explain $68 \%$ of the variance of CORP-GOV and $63 \%$ of the variance of FIN-PERF. Firms with larger investment opportunities have more effective governance and better performance. The main finding, though, of table 2 , is shown in bold and concerns the residual covariance between governance and performance, i.e., the covariance after controlling for the effect of the investment opportunities. Our estimate is -0.05 , with a $t$-value of -0.61 . Based on this result we cannot reject the null hypothesis; the result provides support for the equilibrium view due to Demsetz (1983).

In the first column of table 3 we list the proxy variables of CORP-GOV, FIN-PERF and INV-OPP. In the next three columns we show the regression coefficients associated with the latent variable shown at the top of the column. In the final column, we show the $\mathrm{R}^{2}$ of the regression of the proxy on the latent variable, which is a measure of the quality of one particular variable as a proxy for the underlying latent variable by which it is driven. 
TABLE 2. The Relationship between Corporate Governance, Financial Performance, and Investment Opportunities

\begin{tabular}{lccc}
\hline & INV-OPP & cov. matrix of error terms & $R^{2}$ \\
\hline CORP-GOV & 0.83 & 0.32 & 0.68 \\
FIN-PERF & $(11.58)$ & $(2.91)$ & 0.63 \\
\hline
\end{tabular}

Note: This table shows the estimation results, with t-statistics in parentheses, for the top two equations in table 1, for a cross-section of time-series averages of 1551 U.S. firms, for the period 2000-2008. The first column shows the effect of changes in the investment opportunity set on corporate governance and financial performance. Column two and three constitute the covariance matrix of the error terms of the two equations. Our focus is on the conditional covariance between governance and financial performance, highlighted in boldface above. The chi-square value is 204.8, with 26 degrees of freedom; the high value is due to the combination of a large sample size and a model that is only an approximation, like every model. The normed fit index is 0.712 ; the RMSEA is 0.067 , with $p \leq 0.05$. Sources: see appendix B.

We interpret the latent variable CORP-GOV as measuring the effectiveness of effective corporate governance arrangements, the higher the value the more effective the arrangements. The coefficient of the regression of BSIZE on CORP-GOV is large, positive and highly significant. Under our interpretation of CORP-GOV, this result indicates that larger boards of directors are associated with more effective of corporate governance arrangements. This result supports the previous results by Coles, Daniel, and Naveen (2008). However, the size effect does decrease as BSIZE increases since BSIZE is expressed in logs.

The regression coefficient of CEO-COMP on CORP-GOV is negative and highly significant, indicating that corporate governance is less effective, the larger the compensation packages are.

The large and positive coefficient of the regression of INV-INST on CORP-GOV provides support for the conjecture that share ownership by institutional investors is influenced by the firm's corporate governance arrangements, cf. Bushee, Carter, and Gerakos (2014) and McCahery, Starks, and Sautner (2016).

Judging by the $R^{2}$, the proxy measuring management share ownership, SHR-OWN, is by far the weakest of the four proxies of CORP-GOV. In addition, the sign of the regression coefficient is negative, implying that as corporate governance becomes more 
TABLE 3. Estimations of Measurement Equations of Corporate Governance, Financial Performance, and Investment Opportunities

\begin{tabular}{|c|c|c|c|}
\hline & CORP-GOV & FIN-PERF & INV-OPP \\
\hline BSIZE & $\begin{array}{c}0.67 \\
(14.90) \\
-0.45\end{array}$ & & \\
\hline CEO-СOMP & $\begin{array}{c}(-11.00) \\
0.78\end{array}$ & & \\
\hline INST-INV & & & \\
\hline SHR-OWN & $(-4.48)$ & & \\
\hline VOL & & $\begin{array}{c}-0.73 \\
(-18.00) \\
0.37\end{array}$ & \\
\hline STK-RET & & & \\
\hline FCF & & (15.46) & \\
\hline SPINDEX & & & $\begin{array}{c}0.45 \\
(13.79) \\
-0.15\end{array}$ \\
\hline RD-SE & & & $\begin{array}{c}(-3.49) \\
0.54\end{array}$ \\
\hline MTOB & & & (10.40) \\
\hline
\end{tabular}

Note: This table shows the estimation results for the bottom ten equations in table 1 , for a cross-section of time-series averages of 1551 U.S. firms, for the period 2000-2008. The latent variables are corporate governance (CORP-GOV), financial performance (FIN-PERF), and the investment opportunity set (INV-OPP). The observed proxies for corporate governance are board size (BSIZE), CEO compensation (CEO-COMP), institutional investors (INST-INV), and outstanding shares held by management (SHR-OWN). The observed proxies for financial performance are stock return volatility (VOL), stock returns (STK-RET), and free cash flow (FCF). The observed proxies for the investment opportunity set are index category (SPINDEX), investments in intangible assets (RD-SE), and market-to-book value (MTOB). For detailed definition of the sources and proxy variable construction, we refer to Section IV and appendix B; $t$-statistics are in parentheses.

effective, share ownership decreases. This result would suggest that corporate governance considerations do not play a significant role in determining share ownership by management. This is rather surprising given the importance that the literature has given to the study of share ownership by management as a mechanism for mitigating conflicts of interest. One interpretation of the result is that the productivity of share 
ownership in dealing with conflicts of interest, especially for larger firms, is relatively low. Share ownership is a costly way of trying to solve a problem that can apparently be solved more effectively by other instruments such as options.

The estimated regression coefficients of VOL, STK-RET and FCF on FIN-PERF are all statistically significant and the $R^{2}$ of the three regressions are reasonably high, ranging from 0.30 to 0.53 , suggesting that all three proxies are plausible functions of the same underlying latent variable. In the data, STK-RET and FCF are positively correlated but both are negatively correlated to VOL. Accordingly, the regression results indicate that STK-RET and FCF are increasing in FIN-PERF, and that VOL is decreasing in FIN-PERF. This result is consistent with the conjecture of Black (1976) that volatility and stock returns are inversely related because rising stock prices decrease leverage, which tends to decrease volatility.

The results of regressing proxies on INV-OPP have one surprise, and that is that RD-SE is negatively related to INV-OPP. In the data, research and development expenditures scaled by total assets are negatively correlated with SPINDEX, a proxy of size and complexity, indicating that as firms get larger and more complex, RD-SE expenditures increase at lower rate than the increase in the firm's size. Thus the results indicate that when the firm's investment opportunities increase, research and development expenditures tend to increase less than proportionally. Why this is the case is not immediately evident.

As a final, step we estimate the unconditional correlation between corporate governance and firm financial performance by dropping INV-OPP from the model. The results are very similar to the results for the full model as reported above and are available from the authors on request. The unconditional correlation between CORP-GOV and FIN-PERF is 0.694 , with a $t$-value of 17.17 . Thus, our main result showing that corporate governance and firm performance are conditionally unrelated is not due to governance and performance being generally unrelated.

\section{Conclusion}

Based on our empirical results, we conclude that corporate governance arrangements and firm performance, on average, are the result of firms making value-maximizing decisions subject to constraints. The outcome 
of these decisions represent an optimum.

We reach this conclusion by taking a fairly simple approach to testing hypotheses when the true variables of interest are either unobservable or latent, or can only be measured with error and there are structural relations between these variables. Given that in empirical corporate finance very many areas of interest are covered by this description, we believe that the approach can fruitfully be applied to a wide range of research questions.

Our results have clear policy implications for the regulation of corporate governance. In fact, the results imply that policies mandating changes in corporate governance arrangements which if binding from above are likely to have negative effects on firm performance. This is ironic since these policy changes are often promoted as being beneficial for shareholders.

Accepted by: Prof. P. Theodossiou, Editor-in-Chief, February 2017

\section{Appendix A. Deriving the reduced form}

In this appendix we show how the reduced form equation (4) can be derived from the structural, three-equation model (1), (2) and (3) introduced in section III,

$$
\begin{gathered}
G_{i, \mathrm{OPT}}=\kappa_{\mathrm{OPT}}+\theta_{\mathrm{OPT}} I_{i} \\
G_{i}=\kappa+\theta I_{i}+u_{1 i} \\
F_{i}=\alpha+\lambda I_{i}+\beta\left(G_{i}-G_{i, \mathrm{OPT}}\right)^{2}+u_{2 i}
\end{gathered}
$$

In the derivation, we use the fact that third moments are zero for normally distributed random variables. By substitution of (5) and (6) in (7) we obtain, with $\mu_{I} \equiv \mathrm{E}\left(\mathrm{I}_{i}\right)$ as before and $\sigma_{I}^{2} \equiv \mathrm{E}\left(I_{i}-\mu_{I}\right)^{2}$, 


$$
\begin{aligned}
F_{i} & =\alpha+\lambda I_{i}+\beta\left[\left(\kappa-\kappa_{\mathrm{OPT}}\right)+\left(\theta-\theta_{\mathrm{OPT}}\right) I_{i}+u_{1 i}\right]^{2}+u_{2 i} \\
& =\left(\alpha+\lambda \mu_{I}\right)+\lambda \widetilde{I}_{i}+\beta\left[\left\{\left(\kappa-\kappa_{\mathrm{OPT}}\right)+\left(\theta-\theta_{\mathrm{OPT}}\right) \mu_{\mathrm{I}}\right\}\right. \\
& \left.+\left(\theta-\theta_{\mathrm{OPT}}\right) \widetilde{I}_{i}+u_{1 i}\right]^{2}+u_{2 i} \\
& \equiv \alpha_{*}+\lambda \widetilde{I}_{i}+\beta\left[c+\Delta_{\theta} \widetilde{I}_{i}+u_{1 i}\right]^{2}+u_{2 i} \\
& =\alpha_{*}+\lambda \widetilde{I}_{i}+\beta\left[c^{2}+\Delta_{\theta}^{2} \tilde{I}_{i}^{2}+u_{1 i}^{2}+2 c \Delta_{\theta} \widetilde{I}_{i}+2 c u_{1 i}+2 \Delta_{\theta} \widetilde{I}_{i} u_{1 i}\right]+u_{2 i} \\
& =\left(\alpha_{*}+\beta c^{2}\right)+\left(\lambda+2 \beta c \Delta_{\theta}\right) \widetilde{I}_{i} \\
& +\beta\left[\Delta_{\theta}^{2} \widetilde{I}_{i}^{2}+u_{1 i}^{2}+2 c u_{1 i}+2 \Delta_{\theta} \widetilde{I}_{i} u_{1 i}\right]+u_{2 i} \\
& =\left(\alpha_{*}+\beta c^{2}+\beta \Delta_{\theta}^{2} \sigma_{I}^{2}+\beta \sigma_{u 1}^{2}\right)+\left(\lambda+2 \beta c \Delta_{\theta}\right) \widetilde{I}_{i} \\
& +\beta\left[\Delta_{\theta}^{2}\left(\widetilde{I}_{i}^{2}-\sigma_{I}^{2}\right)+\left(u_{1 i}^{2}-\sigma_{u 1}^{2}\right)+2 c u_{1 i}+2 \Delta_{\theta} \widetilde{I}_{i} u_{1 i}\right]+u_{2 i} \\
& \equiv \alpha_{* *}+\lambda^{\prime} \widetilde{I}_{i}+\left(\beta w_{i}+u_{2 i}\right) \\
& \equiv \alpha_{* *}+\lambda^{\prime} \widetilde{I}_{i}+e_{i}
\end{aligned}
$$

Notice that $\underset{\tilde{I}}{\mathrm{E}}\left(e_{i}\right)=0$, and also $\mathrm{E}\left(\widetilde{I}_{i} e_{i}\right)=0$ since $\mathrm{E}\left(\tilde{I}_{i}^{3}\right)=0$. Substituting for $\tilde{I}_{i}$ yields, letting $\alpha^{\prime} \equiv \alpha_{* *}-\lambda^{\prime} \mu_{I}$,

$$
F_{i}=\alpha^{\prime}+\lambda^{\prime} I_{i}+e_{i}
$$

The reduced form of the model consists of now is the is We jointly estimate the equations for $G_{i}$ and $F_{i}$ and are interested in the covariance between their error terms, $u_{1 i}$ and $e_{i}$. With $\gamma \equiv\left(u_{1 i} u_{2 i}\right)$ there holds

$$
\mathrm{E}\left(u_{1 i} e_{i}\right)=\beta \mathrm{E}\left(u_{1 i} w_{i}\right)+\gamma=2 \beta c \sigma_{u 1}^{2}+\gamma
$$

with $c=\left(\kappa-\kappa_{\mathrm{OPT}}\right)+\left(\theta-\theta_{\mathrm{OPT}}\right) \mu_{\mathrm{I}}$, as above. 


\section{Appendix B. Definition and sources of the observable variables}

BSIZE: the logarithm of 1 plus the number of members of the board of directors. Measured as the logarithm of 1 plus the number of board members. Source: Riskmetrics.

CEO-COMP: Annual total compensation of the CEO divided by total assets. Sources: Execucomp and Compustat.

FCF: free cash-flow. Operating income after depreciation divided by the market value of equity. Source: Compustat.

INST-INV: the logarithm of 1 plus the number of institutional investors holding shares in the firm. Source: Thompson-Reuters Institutional.

MTOB: the market-to-book ratio. Measured as the market value of the firm divided by its book value. Source: Compustat.

RD-SE: the sum of expenditures on research and development, selling expenses and advertising divided by total assets. Source: Compustat.

SHR-OWN: percentage of total shares owned by the executive officers of the firm. Source: Execucomp.

SPINDEX: a categorical variable indicating the whether or not the firm is included of one of the three sub-indices constituting the S\&P1500 index and if so, in which one of the three indices. The possible values for the variable are: $0=$ not included in the index; $1=\mathrm{S} \& \mathrm{P} 400 \quad$ (small capitalization firms); 2=S\&P600 (mid-size capitalization firms); $3=$ S\&P500 (large capitalization firms). Source: Compustat.

STK-RET: stock market return. Measured as the annualized total return on common stock estimated using with 36 monthly observations. Source: CRSP.

VOL: standard deviation of returns. Estimated using 36 months of total returns observations. Source: CRSP. 
Relation Between a Firm's Corporate Governance and Financial Performance? 349

\section{Appendix C. Descriptive statistics}

TABLE 4. Mean, standard deviation, minimum, and maximum of the proxy variables

\begin{tabular}{lcccr}
\hline & mean & s.d. & min. & max. \\
\hline BSIZE & 2.164 & 0.252 & 1.609 & 2.708 \\
CEO-COMP & 3.155 & 3.842 & 0.080 & 23.689 \\
INST-INV & 5.098 & 1.097 & 0.000 & 7.065 \\
SHR-OWN & 3.023 & 6.989 & 0.000 & 38.700 \\
VOL & 0.122 & 0.058 & 0.041 & 0.332 \\
STK-RET & 0.087 & 0.183 & -0.332 & 0.691 \\
FCF & 0.115 & 0.081 & -0.194 & 0.333 \\
SPINDEX & 2.051 & 0.780 & 0.000 & 1.016 \\
RD-SE & 0.291 & 0.220 & 0.000 & 1.016 \\
MTOB & 1.921 & 1.174 & 0.670 & 7.108 \\
\hline
\end{tabular}

Note: Figures based on the original data $(N=8567)$, before winsorizing, adjusting for industry and time effects, and averaging over time. The observed proxies for corporate governance are board size (BSIZE), CEO compensation (CEO-COMP), institutional investors (INST-INV), and outstanding shares held by management (SHR-OWN). The observed proxies for financial performance are stock return volatility (VOL), stock returns (STK-RET), and free cash flow (FCF). The observed proxies for the investment opportunity set are index category (SPINDEX), investments in intangible assets (RD-SE), and market-to-book value (MTOB). For detailed definition of the sources and proxy variable construction, we refer to Section IV and appendix B. 


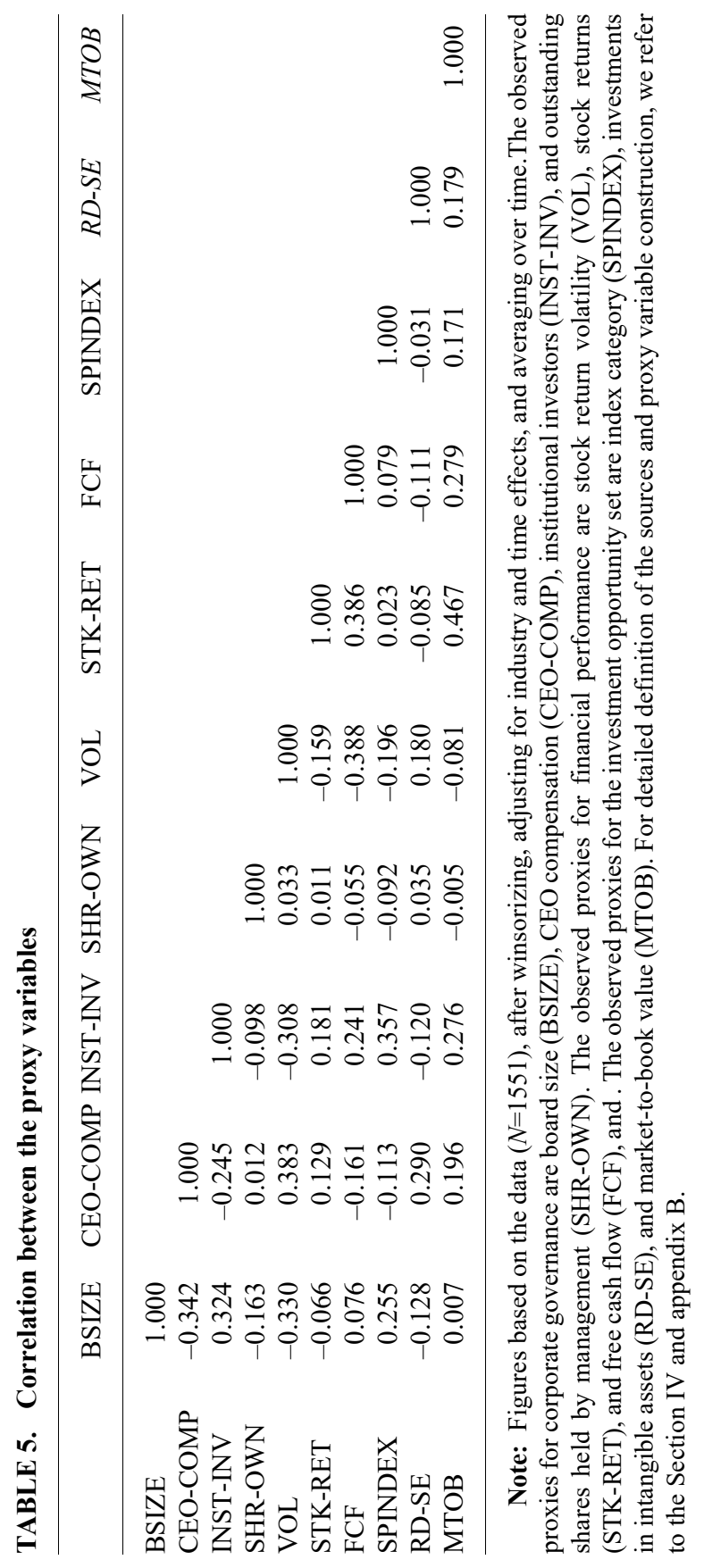




\section{References}

Adams, R.; Hermalin, B.; and Weisbach, M. 2010. The role of boards of directors in corporate governance: a conceptual framework and survey. Journal of Economic Literature 48:58-107.

Ahern, K., and Dittmar, A. 2012. The changing of the boards: The impact on firm valuation of mandated female board representation. Quarterly Journal of Economics 127:137-197.

Almazan, A., and Suarez, J. 2003. Entrenchment and severance pay in optimal governance structures. The Journal of Finance 58:519-547.

Ang, A.; Hodrick, R.; Xing, Y.; and Zhang, X. 2006. The cross-section of volatility and expected returns. Journal of Finance 61:259-299.

Bebchuk, L., and Fried, J. 2004. Pay without performance. Harvard University Press.

Berle, A., and Means, G. 1932. The modern corporation and private property. Macmillan.

Bhagat, S., and Bolton, B. 2008. Corporate governance and firm performance. Journal of Corporate Finance 14:257-273.

Bhagat, S.; Bolton, B. J.; and Romano, R. 2008. The promise and peril of corporate governance indices. Columbia Law Review 108:1803-1882.

Black, F. 1976. Studies of stock price changes. Proceedings of the 1976 Meetings of the American Statistical Association.

Bøhren, O., and Staubo, S. 2014. Does mandatory gender balance work? Changing organizational form to avoid board upheaval. Journal of Corporate Finance, 28:152-168.

Boone, A. L.; Field, L. C.; Karpoff, J. M.; and Raheja, C. G. 2007. The determinants of corporate board size and composition: An empirical analysis. Journal of Financial Economics 85:66-101.

Brickley, J. A., and Zimmerman, J. L. 2010. Corporate governance myths: Comments on Armstrong, Guay, and Weber. Journal of Accounting and Economics 50: 235-245.

Bushee, B.; Carter, M.; and Gerakos, J. 2014. Institutional Preferences for Corporate Governance Mechanisms. Journal of Management Accounting Research 26: 123-149.

Chhaochharia, V., and Grinstein, Y. 2007. Corporate governance and firm value: The impact of the 2002 governance rules. Journal of Finance 62:1789-1825.

Cohen, L.; Frazzini, A.; and Malloy, C. 2012. Hiring cheerleaders: Board appointments of independent directors. Management Science 58:1039-1058.

Coles, J.; Daniel, N.; and Naveen, L. 2008. Boards: does one size fit all? Journal of Financial Economics 87:329-356.

Coles, J.; Lemmon, M.; and Meschke, F. 2012. Structural models and endogeneity in corporate finance: The link between managerial ownership 
and corporate performance. Journal of Financial Economics 103:149-168.

Cornelli, F.; Kominek, Z.; and Ljungqvist, A. 2013. Monitoring managers: Does it matter? Journal of Finance 68:431-481.

Cremers, K., and Nair, V. 2005. Governance mechanisms and equity prices. Journal of Finance 60:2859-2894.

Daines, R. M.; Gow, I. D.; and Larcker, D. F. 2010. Rating the ratings: How good are commercial governance ratings? Journal of Financial Economics 98:439-461.

Demsetz, H. 1983. The structure of ownership and the theory of the firm. Journal of Law and Economics 26:375-390.

Demsetz, H., and Lehn, K. 1985. The structure of corporate ownership: Causes and consequences. Journal of Political Economy 93:1155-1177.

Demsetz, H., and Villalonga, B. 2001. Ownership structure and corporate performance. Journal of Corporate Finance 7:209-233.

Dichev, I., and Tang, V. 2009. Earnings volatility and earnings predictability. Journal of Accounting and Economics 47:160-181.

Dittmar, A., and Mahrt-Smith, J. 2007. Corporate governance and the value of cash holdings. Journal of Financial Economics 83:599-634.

Duchin, R.; Matsusaka, J. G.; and Ozbas, O. 2010. When are outside directors effective? Journal of Financial Economics 96:195-214.

Dybvig, P.H. and Warachka, M. 2008. Tobin's Q Does Not Measure Firm Performance: Theory, Empirics, and Alternatives. SSRN eLibrary.

Erickson, T., and Whited, T. 2006. On the accuracy of different measures of Q. Financial Management 35:5-33.

Eckbo, E.B.; Nygaard, K; and Thorbrun, K.S. 2016. Does Gender-Balancing the Board reduce Firm Value? CEPR Discussion paper No DP 11176.

Fahlenbrach, R. 2009. Shareholder rights, boards, and CEO compensation. Review of Finance 13:81-113.

Fich, E., and Shivdasani, A. 2006. Are busy boards effective monitors? Journal of Finance 61:689-724.

Frydman, C., and Saks, R. 2010. Executive compensation: A new view from a long-term perspective, 1936-2005. Review of Financial Studies 23:2099-2138.

Gabaix, X., and Landier, A. 2008. Why has CEO pay increased so much? Quarterly Journal of Economics 123:49-100.

Gaver, J. J., and Gaver, K. M. 1993. Additional evidence on the association between the investment opportunity set and corporate financing, dividend, and compensation policies. Journal of Accounting and Economics 16:125-160.

Gompers, P.; Ishii, J.; and Metrick, A. 2003. Corporate governance and equity prices. Quarterly Journal of Economics 118:107-155.

Guay,W. 1999. The sensitivity of CEO wealth to equity risk: an analysis of the magnitude and determinants. Journal of Financial Economics 53:43-71.

Hartzell, J., and Starks, L. 2003. Institutional investors and executive 
compensation. Journal of Finance 58:2351- 2374.

Hermalin, B., and Weisbach, M. 2003. Board of directors an endogenously determined institution: a survey of the economic literature. Economic Policy Review of the Federal Reserve Bank of New York 9:7-26.

Holmstrom, B. 2005. Pay without performance and the managerial power hypothesis: A comment. Journal of Corporation Law 30:703-715.

Holmstrom, B., and Tirole, J. 1993. Market liquidity and performance monitoring. Journal of Political Economy 101:678-709.

Jensen, M. 1986. Agency costs of free cash flow, corporate finance, and takeovers. American Economic Review 76:323-329.

Jensen, M. 1993. The modern industrial revolution, exit, and the failure of internal control systems. Journal of Finance 48:831-880.

Jensen, M., and Meckling, W. 1976. Theory of the firm: Managerial behavior, agency costs and ownership structure. Journal of Financial Economics 3:305-360.

Johnson, S. A.; Moorman, T. C.; and Sorescu, S. 2009. A reexamination of corporate governance and equity prices. Review of Financial Studies 22:4753-4786.

Leary, M., and Roberts, M. 2014. Do peer firms affect corporate financial policy? Journal of Finance 69:139-178.

Lehn, K.; Patro, S.; and Zhao, M. 2009. Determinants of the size and composition of us corporate boards: 1935-2000. Financial Management 38:747-780.

Linck, J. S.; Netter, J.; and Yang, T. 2008. The determinants of board structure. Journal of Financial Economics 87:308-328.

McCahery, J.; Sautner, Z.; and Starks, L. 2016. The Corporate Governance Preferences of Institutional Investors. Journal of Finance 71:2905-2932.

Morck, R.; Schleifer, A.; and Vishny, R. 1998. Management ownership and market valuation. an empirical analysis. Journal of Financial Economics 20:293-315.

Murphy, K. J. 2013. Executive compensation: where we are and how we got there. In Constantinides, G., Harris, M., and Stulz, R., editors, Handbook of the Economics of Finance, Vol 2A ElsevierScience, North-Holland.

Myers, S. 1977. Determinants of corporate borrowing. Journal of Financial Economics, 5:147-175.

Roberts, M., and Whited, T. 2013. Endogeneity in empirical corporate finance. In Constantinides, G., Harris, M., and Stulz, R., editors, Handbook of the Economics of Finance, Volume 2A. Elsevier.

Roll, R., and Weston, F. 2008. Average and marginal Tobin's Q as indicators of future growth opportunities, expected return and risk. WP 2008-10. UCLA-Anderson School of Management

Ryan, H., and Wiggins, R. 2004. Who is in whose pocket? Director compensation, board independence, and barriers to effective monitoring. Journal of Financial Economics 73:497-524. 
Skrondal, A., and Rabe-Hesketh, S. 2004. Generalized latent variable modeling. Chapman \& Hall.

Stráska, M., and Waller, G. 2010. Do antitakeover provisions harm shareholders? Journal of Corporate Finance 16:487-497.

Tobin, J., and Brainard, W. 1977. Asset markets and the cost of capital. In Nelson, R., and Balassa, B., editors, Economic progress: private values and public policy-Essays in honour of William Feller. North Holland.

Wansbeek, T., and Meijer, E. 2000. Measurement error and latent variables in econometrics. North-Holland.

Wintoki, M. B.; Linck, J. S.; and Netter, J. M. 2012. Endogeneity and the dynamics of internal corporate governance. Journal of Financial Economics 105:581-606.

Yermack, D. 1996. Higher market valuation of companies with a small board of directors. Journal of Financial Economics 40:185-211. 